\title{
Clinicians' Feedback on Patient/Carer Experience After Switching of Growth Hormone Treatment in Pediatric Patients During COVID-19
}

\author{
Joanne Blair (D) \\ Kelly Warth ${ }^{2}$ \\ Yashasvi Suvarna ${ }^{3}$ \\ Marco Cappa (iD) \\ 'Department of Endocrinology, Alder \\ Hey Children's NHS Foundation Trust, \\ Liverpool, UK; ${ }^{2}$ Instar, London, UK; \\ ${ }^{3}$ Global Medical Affairs, Novo Nordisk \\ Global Business Services (GBS), \\ Bangalore, India; ${ }^{4}$ Endocrinology Unit, \\ Bambino Gesù Children's Hospital, \\ IRCCS, Rome, Italy
}

Purpose: This study investigated why some clinicians switched growth hormone (GH) brands in pediatric patients with GH-related disorders to Norditropin ${ }^{\circledR}$ since the start of the COVID-19 pandemic, the clinicians' perceptions of the results, and whether observations from this period of disruption could inform clinical practice in the future.

Patients and Methods: Clinicians $(\mathrm{N}=106)$ from the UK, France, Italy, and Japan who had switched at least one patient to Norditropin ${ }^{\circledR}$ from a GH therapy manufactured by a different pharmaceutical company between February and November 2020 participated. They completed an online survey and submitted patient report forms for up to three switched patients. Results: Since the start of COVID-19, 39-54\% of the reported consultations were virtual (ie, via telephone or online means) in the UK, France, and Italy. Overall, 17\% of patients seen by respondents in the survey were switched to a different $\mathrm{GH}$ brand; approximately two-thirds of switches were to Norditropin ${ }^{\circledR}$. Clinicians' top considerations in choosing a GH brand were patient/carer feedback, patient support programs, and the need for easy-to-use therapies in the context of virtual consultations. The top reasons for switching patients to Norditropin ${ }^{\circledR}$ included ease of use, device features and benefits, better patient/carer feedback, and ease of training in device use via virtual consultations. Norditropin ${ }^{(B)}$ was considered suitable for use in virtual or in-person consultations or a mixture of both. Based on patient/ carer feedback, $66 \%$ of clinicians believed that patients preferred Norditropin ${ }^{\circledR}$ to their previous therapy in terms of overall satisfaction.

Conclusion: In this survey, key considerations in prescribing GH therapy were ease of use and acceptability to patients and carers. If virtual consultations increasingly replace in-person ones, ease in training patients/carers in device use will be particularly important. A majority of clinicians considered that their patients preferred Norditropin ${ }^{\circledR}$ to their previous therapy. Keywords: growth disorders, somatropin, virtual consultations, ease of use, Norditropin ${ }^{\circledR}$

\section{Plain Language Summary}

This study surveyed 106 clinicians in the UK, France, Italy, and Japan who treat children with growth hormone $(\mathrm{GH})$-related disorders. We asked them for their reasons for switching patients to Norditropin ${ }^{\circledR}$ from a different GH brand since the start of COVID-19. Overall, the clinicians had treated 5699 children with GH and had switched $17 \%$ these children to a different GH brand between February and November 2020; 36\% of consultations had been virtual (by telephone or online).

The key considerations for choosing a GH brand were patient/carer feedback, the patient support programs offered by pharmaceutical companies, and the need for therapies to be easy to use in the context of virtual consultations. Clinicians' top reasons for switching patients to
Department of Endocrinology, Alder Hey

Children's NHS Foundation Trust,

Liverpool, LI2 2AP, UK

Tel +44 I5I 2525335

$\mathrm{Fax}+44$ I5I 2824606

Email Jo.Blair@alderhey.nhs.uk 
Norditropin $^{\circledR}$ during COVID-19 were as follows: it was a superior device that was easier for patients to use (53\%); device features and benefits (39\%); better patient/carer feedback $(31 \%)$; and ease of training patients virtually to use the device $(24 \%)$. Norditropin $^{\circledR}$ was the clinicians' most frequent choice for use in virtual or in-person consultations or a mixture of both. Based on a small sample of report forms for patients who had switched to Norditropin $^{\circledR}$, two-thirds of clinicians believed that patients preferred Norditropin ${ }^{\circledR}$ to their previous therapy.

In this survey, Norditropin ${ }^{\circledR}$ demonstrated the ability to meet key requirements for GH therapy: ease of use, acceptability to patients/carers, and ease in training users via virtual consultations.

\section{Introduction}

The COVID-19 pandemic has brought about challenges in many aspects of life around the world. Among these is the impact on healthcare of decreased patient contact with clinicians, in particular on the management of chronic diseases that require long-term monitoring and follow-up. A prime example is growth hormone $(\mathrm{GH})$-related disorders that are treated with GH, such as GH deficiency in children and adults. Even before the advent of COVID-19, the management of these disorders faced many challenges, ${ }^{1-3}$ including dealing with the specific needs of children, as well as parents' fears.

Recombinant GH (somatropin) is indicated for the treatment of a number of GH-related disorders. ${ }^{4,5}$ Several $\mathrm{GH}$ products and administration devices are available. All $\mathrm{GH}$ therapies currently approved for use in children require daily subcutaneous injection, although a number of once-weekly GH products are expected to enter the therapeutic landscape in the next few years. Norditropin ${ }^{\circledR}$ (somatropin, Novo Nordisk A/S, Denmark), a daily GH therapy, is indicated for GH deficiency (GHD) in children and adults, growth failure in Noonan syndrome, Turner syndrome, growth disturbance in children born small for gestational age, and growth retardation in pre-pubertal children due to chronic kidney disease; the approved indications vary by country. In addition, devices differ in the various countries $\left(\right.$ FlexPro $^{\circledR}$, NordiFlex $^{\circledR}$, NordiLet $^{\circledR}$, Norditropin $^{\circledR}$ SimpleXx ${ }^{\circledR}$ used with NordiPen ${ }^{\circledR}$ ), but the drug is already reconstituted in all and can be stored at room temperature for up to 21 days after first use. ${ }^{6}$

During 2020, supply shortages with a different $\mathrm{GH}$ brand, ${ }^{7}$ coupled with the COVID-19 pandemic, resulted in clinicians reporting proactive switches to Norditropin ${ }^{\circledR}$ from other $\mathrm{GH}$ treatments. The objectives of this study were to investigate the key reasons driving clinicians to switch pediatric patients to Norditropin ${ }^{\circledR}$ since the start of COVID-19; to assess clinicians' ratings of patients' quality of life (QoL) after the switch to Norditropin ${ }^{\circledR}$; and to determine whether the results can provide any useful information for $\mathrm{GH}$ treatment in general during and after the pandemic.

\section{Patients and Methods}

A survey was carried out in the UK, France, Italy, and Japan by the market research company Instar. It was carried out between November 2020 and February 2021, and the data collected included patients switched to Norditropin $^{\circledR}$ by clinicians between February and November 2020. Respondents were invited to participate at random from an established panel of healthcare professionals (HCPs) already identified as willing to participate in market research (See Supplement).

The respondents comprised endocrinologists, pediatricians, and endocrinology nurses (the latter in the UK only, where they provide device training and ongoing support). All were involved in pediatric endocrinology, spent $\geq 50 \%$ of their professional time in direct patient care, and had switched at least one pediatric patient to Norditropin ${ }^{\circledR}$ from a different GH brand since the start of COVID-19. Full recruitment criteria are shown in the Supplement. Respondents completed a 15-minute online questionnaire (an abbreviated version is provided in the Supplement). Each respondent was asked to complete between one and three patient record forms (PRFs) for patients aged 4-18 years old, treated with a GH therapy that was not Norditropin $^{\circledR}$ and who were switched to Norditropin ${ }^{\circledR}$ since the start of COVID-19 (defined as February-March 2020).

No a priori calculations of sample size were performed; recruitment of potential respondents continued until a sample size of at least 22 respondents was obtained for each country. The results are presented descriptively for the overall sample and by country, patient age (4-9, 1012, 13-18 years), and self-injection status; no statistical analyses are reported.

All relevant privacy requirements were adhered to, including informed consent, and the European Pharmaceutical Market Research Association guidelines were followed. Respondents were paid for completing the survey in line with fair market value within the industry. 


\section{Results}

\section{Context in Which GH Treatment Was Given}

A total of 106 clinicians responded to the survey (Table 1). Endocrinologists were the main survey participants in the UK, France, and Italy, while pediatricians (as opposed to pediatric endocrinologists) made up most of the sample in Japan. Between them, the clinicians had used GH in the treatment of 5699 children with GH-related disorders since the start of COVID-19 (Table 2).

The format of patient contacts (face-to-face or virtual, ie, via telephone or online means) since COVID-19 started is shown in Table 1. In the UK, Italy, and France, virtual means were used for patient engagement in 39-54\% of appointments, whereas only $10 \%$ of appointments were conducted virtually in Japan.

\section{Clinicians' Attitudes Towards the Prescribing of GH Therapy During COVID-19}

Clinicians' attitudes towards the prescribing of GH therapy were examined by asking them to reply "yes" or "no" to a series of statements. The results are shown in Figure 1.

Clinicians in all the countries stated that patient/carer feedback on their GH therapy was important to the clinician in deciding whether to switch the patient to a different $\mathrm{GH}$ brand. Similarly, patient/carer feedback on their device was also an important factor in the clinician's decision whether to switch the patients to a different $\mathrm{GH}$ device. The next most highly rated considerations were "Patient support program/materials provided by a pharmaceutical company are important in deciding whether to switch to a different $\mathrm{GH}$ brand/ device" and "Telemedicine has put greater emphasis on the importance of an easy-to-use and patient-friendly device" (the latter especially in Italy).

The respondents were also asked to identify their main or most-commonly prescribed therapy for three patient scenarios: virtual consultations, in-person consultations, or a mixture of these two. The results are shown in Figure 2. Norditropin ${ }^{\circledR}$ was the most frequently mentioned therapy, cited in $48 \%, 41 \%$, and $47 \%$ of the above scenarios, respectively.

\section{Treatment Decisions for Pediatric GH Patients Since the Start of COVID-19}

Table 2 shows the proportion of all patients with diagnosed or suspected GH-related disorders who were treated with GH therapy during the survey period, and the distribution by age category. The proportion of patients with diagnosed or suspected GH-related disorders who were actually treated with GH varied from $46.5 \%$ in Japan to

Table I Characteristics of Survey Respondents and Format of Patient Contacts

\begin{tabular}{|c|c|c|c|c|c|}
\hline Number of Clinicians & Total $N=106$ & UK n=24 & France $n=22$ & Italy $\mathbf{n = 3 0}$ & Japan $n=30$ \\
\hline \multicolumn{6}{|l|}{ Primary medical specialty, \% } \\
\hline Endocrinologist & 69 & 71 & 91 & 93 & 27 \\
\hline Pediatrician & 27 & 13 & 9 & 7 & 73 \\
\hline Endocrinology nurse & 4 & 17 & 0 & 0 & 0 \\
\hline Years in practice, mean & 19.6 & 18.9 & 20.3 & 18.2 & 21.1 \\
\hline \multicolumn{6}{|l|}{ Time spent on tasks, mean, \% } \\
\hline Providing direct patient care & 88 & 82 & 90 & 93 & 85 \\
\hline Performing academic functions & 6 & 6 & 6 & 3 & 7 \\
\hline Administrative functions & 5 & 9 & 4 & 3 & 6 \\
\hline Other professional duties & I & 3 & 0 & I & 2 \\
\hline \multicolumn{6}{|c|}{ Patient contact format since COVID-19, \% } \\
\hline Virtual (video, Zoom, Skype etc) & 19 & 25 & 24 & 24 & 6 \\
\hline Telephone-based & 17 & 29 & 15 & 20 & 4 \\
\hline Total for virtual & 36 & 54 & 39 & 44 & 10 \\
\hline In-office visits & 61 & 44 & 57 & 51 & 89 \\
\hline Home visits & 3 & 2 & 4 & 5 & 1 \\
\hline Total for face-to-face & 64 & 46 & 61 & 56 & 90 \\
\hline
\end{tabular}

Note: Percentages have been rounded. 
Table 2 Numbers of Pediatric Patients with Diagnosed or Suspected GH-Related Disorders Seen and Treated by the Respondents Since the Start of COVID-19 (February/March 2020) Up to the Point When They Completed the Survey, and Distribution by Age

\begin{tabular}{|l|c|c|c|c|c|}
\hline & All & UK & France & Italy & Japan \\
\hline Number of clinicians & 106 & 24 & 22 & 30 & 30 \\
Patients seen with diagnosed or suspected GH-related disorders & 8369 & 1868 & 3033 & 2665 & 803 \\
Patients with GH-related disorders treated with GH & 5699 & 1251 & 1838 & 2236 & 374 \\
Patients with GH-related disorders treated with GH, \% & $68.1 \%$ & $67.0 \%$ & $60.6 \%$ & $83.9 \%$ & $46.5 \%$ \\
\hline Patients by age category (as percent of GH-treated patients) & & & & \\
4-9 years & $31.9 \%$ & $34.1 \%$ & $34.8 \%$ & $25.0 \%$ & $51.4 \%$ \\
I0-I2 years & $35.6 \%$ & $32.4 \%$ & $34.5 \%$ & $39.2 \%$ & $29.9 \%$ \\
I3-I8 years & $32.6 \%$ & $33.5 \%$ & $30.7 \%$ & $35.9 \%$ & $18.7 \%$ \\
\hline
\end{tabular}

Abbreviation: $\mathrm{GH}$, growth hormone.

$83.9 \%$ in Italy. The treated population was evenly distributed between age categories (4-9, 10-12, 13-18 years) in the UK and France. In Italy, the youngest age group made up only $25 \%$ of treated patients, and the middle age group accounted for a slightly higher percentage of patients than the oldest group. In Japan, approximately half of all patients were in the youngest group, and the oldest group had the smallest percentage of patients.

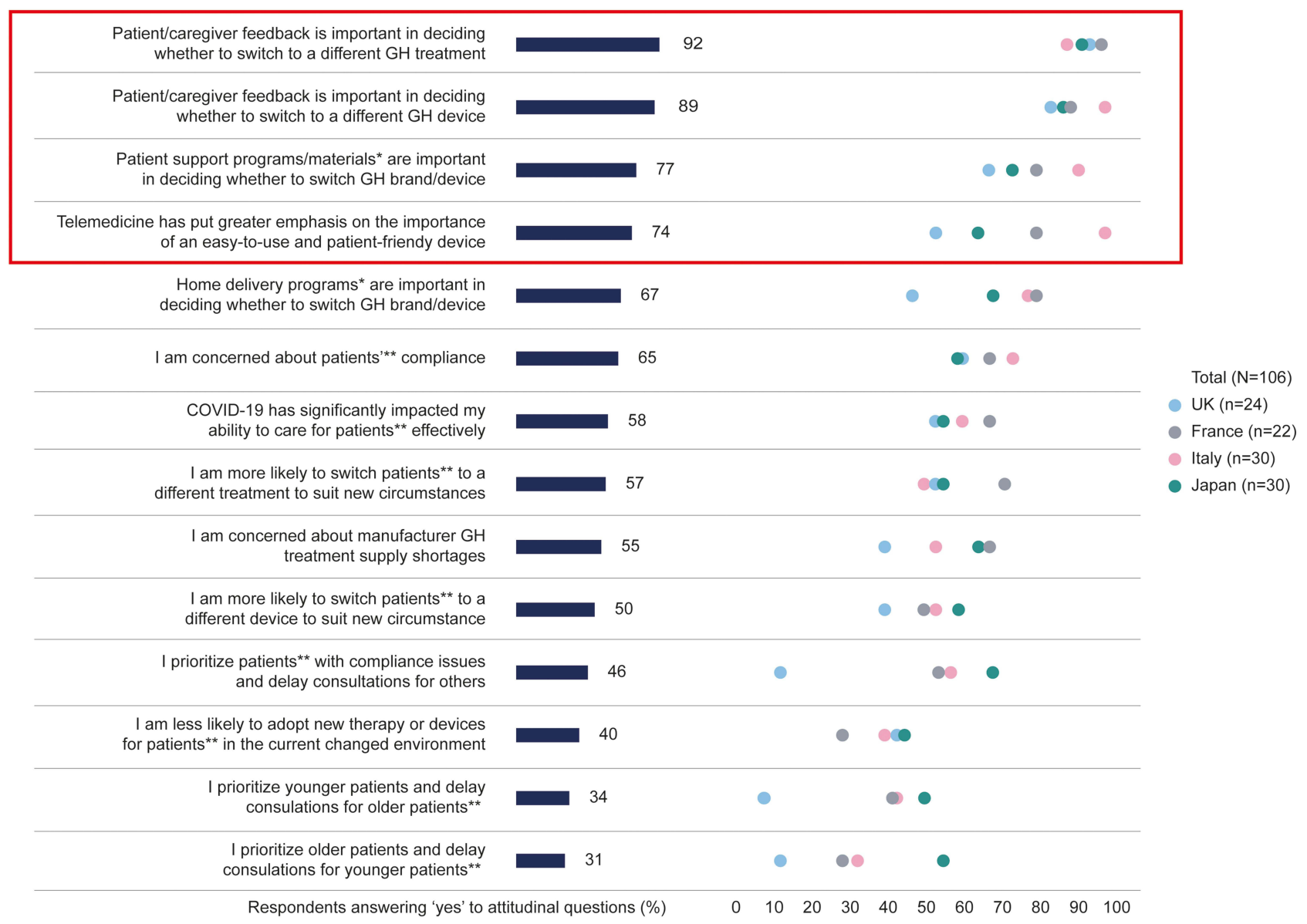

Figure I Clinicians' attitudes towards GH prescribing since COVID-19, shown as percentage of respondents agreeing with the statements. The red box indicates the statements that received the highest agreement from respondents. *Refers to patient support program and home delivery program provided by a pharmaceutical company. **Refers to pediatric patients with $\mathrm{GH}$-related disorders.

Abbreviation: $\mathrm{GH}$, growth hormone. 


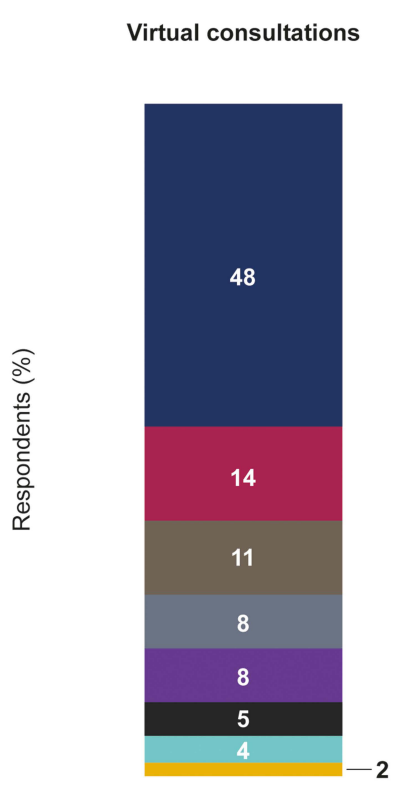

In-person consultations

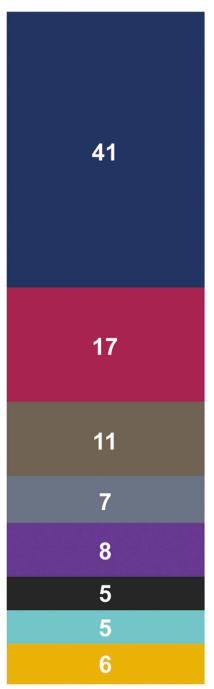

A mix of in-person

and virtual consultations

Norditropin ${ }^{\circledR}$

Genotropin

Saizen ${ }^{\circledR}$

Humatrope ${ }^{\circledR}$

Omnitrope

NutropinAq ${ }^{\circledast}$

Growject $^{\circledR}$

Zomacton ${ }^{\circledR}$

Figure 2 Brands identified by clinicians $(\mathrm{N}=106)$ as their main/most commonly prescribed therapy for three patient scenarios. Shown as a percentage of the responses for

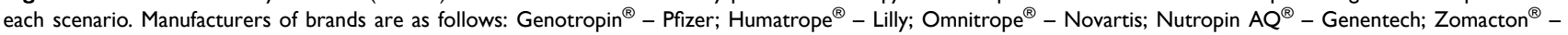
Ferring Pharmaceuticals; Saizen ${ }^{\circledR}-$ Merck; Growject ${ }^{\circledR}-$ JCR Pharmaceuticals.

Respondents were asked about the number of patients switching, initiating new therapy, continuing or discontinuing therapy since COVID-19, and the proportions within each country are shown in Figure 3. Those continuing therapy were the largest group, and new GH therapy initiations were the second largest group, in all countries except Italy (where 33\% of patients initiated new therapy and $25 \%$ continued their therapy). Since the start of COVID-19, among the respondents, $17 \%$ of patients overall were switched to a different GH therapy, ranging from $9 \%$ in the UK to $24 \%$ in Italy. The brands and devices that patients were switched to by the respondents since the start of COVID-19 are shown in Supplementary Figure S1. Around two thirds of switches overall were to $\operatorname{Norditropin~}^{\circledR}$.

\section{Characteristics of Patients Switched to Norditropin ${ }^{\circledR}$}

In total, 217 PRFs were submitted for patients who had been switched to Norditropin ${ }^{\circledR}$. The demographics of the corresponding patients are shown in Table 3 by country, age group, and injection status. For the patients for whom PRFs were received, the peak in volume of switching during 2020 occurred earliest in Japan (February-April), in two peaks in Italy (February and May), and slightly later in the UK (May-June) and France (May-July).

More than half $(123 / 217 ; 57 \%)$ of the PRFs provided were for the youngest age group. Highest mean age was 10.1 years, reported in the UK, and the lowest 8.6 years, reported in Japan. Approximately a third of UK patients were self-injecting, compared with around a quarter in other markets. Around half of older patients were still relying on carers to inject. The proportions of patients in the different age groups and by injection status are shown for each country in Supplementary Table 1.

Table 3 also shows which Norditropin ${ }^{\circledR}$ device patients were switched to. This varied by country, reflecting national differences in device availability and familiarity: FlexPro ${ }^{\circledR}$ was prescribed for all patients in Japan (where only FlexPro ${ }^{\circledR}$ was available) and $64 \%$ in France; NordiFlex $^{\circledR}$ for all patients in Italy (where only Nordiflex ${ }^{\circledR}$ was available) and $56 \%$ in the UK; and NordiPen ${ }^{\circledR}$ for $35 \%$ of patients in the UK and $36 \%$ in France. FlexPro ${ }^{\circledR}$ has only relatively recently become available in the UK and France.

The previous GH brand used, and mean durations of therapy on that brand, are shown in Table 3. Mean duration of previous therapy varied from 29.6 months (Italy) to 

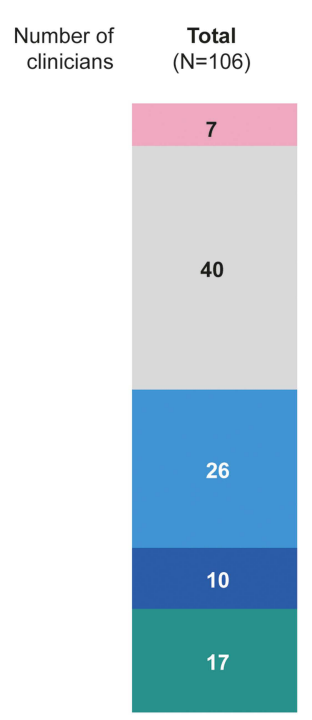

Treatment discontinuation/break

Treatment continuation

New GH treatment initiations

Switch of GH device only

Switch of GH treatment device

Figure 3 Treatment pathway for pediatric GH patients since the start of COVID-19: proportions (\%) of patients switching, initiating new therapy, continuing or discontinuing therapy.

Abbreviation: $\mathrm{GH}$, growth hormone.

34.9 months (France). As expected, the mean duration of therapy was shortest in the youngest age group (26.9 months).

\section{Clinicians' Reasons for Changing GH Therapy to Norditropin ${ }^{\circledR}$ and Estimation of Benefits}

Respondents were asked to select their top three reasons for switching to Norditropin ${ }^{\circledR}$ in the current COVID-19 pandemic environment (Supplementary Figure S2). Respondents most frequently cited a superior device that was easier for patients to use as the main advantage (53\% of PRFs), and the device features and benefits (39\%). Other frequently reported reasons were better patient/carer feedback (31\%), supply issues with the previous therapy $(29 \%)$, and ease of device training via telemedicine $(24 \%)$. Due to the way in which the questionnaire was structured, it is not possible to ascertain the exact number of patients overall who were switched because of the above reasons. For patients who had switched, clinicians were asked how Norditropin ${ }^{\circledR}$ compared to the previous GH brand in terms of the level of training and/or support required from HCPs. The choices available were "superior", "inferior", "no different" or "don’t know" ( was rated as superior by $56 \%$ of respondents overall and by $56 \%$ (UK), 38\% (France), 57\% (Italy), and 71\% (Japan), respectively.

Respondents were then asked to assess patient/carer feedback for Norditropin ${ }^{\circledR}$ versus their previous therapy on a range of aspects. The options were as follows: "Norditropin ${ }^{\circledR}$ superior", "no difference", "previous therapy superior", or "don't know" (Supplementary Figure S4). For most aspects, clinicians considered that patients/ carers preferred Norditropin ${ }^{\circledR}$ versus their previous therapy or considered there was no difference. Only a few clinicians reported that they did not know how patient/ carer feedback rated Norditropin ${ }^{\circledR}$ versus the previous therapy or that they considered that the feedback indicated a preference for the previous therapy over Norditropin $^{\circledR}$. In the clinicians' opinion, the top aspects in which patient/carer feedback rated Norditropin ${ }^{\circledR}$ as superior to previous therapy were as follows: overall patient satisfaction (66\% of PRFs); overall patient preference versus previous device (64\%); and ease of training/learning how to use $(57 \%)$. Based on patient/carer feedback, clinicians considered that treatment adherence (compliance) was better (42\% of PRFs) or equal $(50 \%)$ with Norditropin ${ }^{\circledR}$ versus the previous therapy, or that the previous therapy was superior $(2 \%)$; for $6 \%$ of PRFs, 
Table 3 Patients Switched to Norditropin ${ }^{\circledR}$ : Demographic Characteristics, Norditropin ${ }^{\circledR}$ Device Prescribed, and Previous GH Brand: (a) by Country; (b) by Age and Injection Status

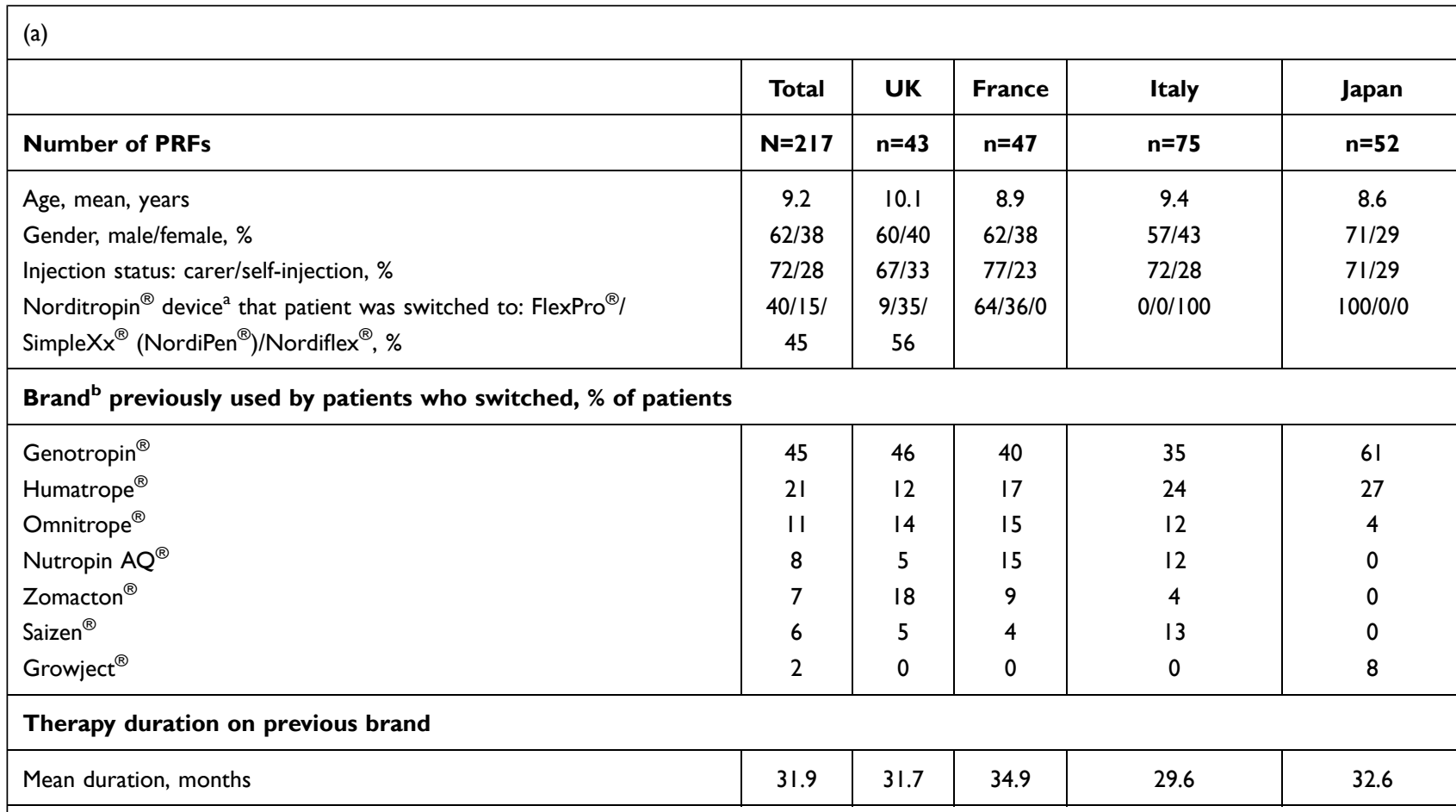

(b)

\begin{tabular}{|c|c|c|c|c|c|}
\hline & \multicolumn{3}{|c|}{ Age Group (Years) } & \multicolumn{2}{|c|}{ Injection Status } \\
\hline & 4-9 & $10-12$ & $13-18$ & Carer-Injected & Self-Injected \\
\hline Number of PRFs & $n=123$ & $n=57$ & $n=37$ & $n=156$ & $n=61$ \\
\hline Age, mean, years & 6.7 & 11.0 & 14.8 & 8.6 & 10.8 \\
\hline Gender, male/female, \% & $54 / 46$ & $81 / 19$ & $62 / 38$ & $61 / 39$ & $66 / 34$ \\
\hline Injection status by age category, carer/self-injection, \% & $83 / 17$ & $61 / 39$ & $51 / 49$ & - & - \\
\hline Norditropin ${ }^{\circledR}$ device ${ }^{a}$ that patient was switched to by category: & $42 / 15 /$ & $39 / 14 /$ & $32 / 16 /$ & $41 / 16 / 43$ & $36 / 11 / 53$ \\
\hline FlexPro $^{\circledR} /$ SimpleXx ${ }^{\circledR}\left(\right.$ NordiPen $\left.^{\circledR}\right) /$ Nordiflex $^{\circledR}, \%$ & 43 & 47 & 52 & & \\
\hline
\end{tabular}

\section{Brand ${ }^{b}$ previously used by patients who switched, $\%$ of patients}

\begin{tabular}{|c|c|c|c|c|c|}
\hline Genotropin $^{\circledR}$ & 51 & 39 & 26 & 33 & 49 \\
\hline Humatrope $^{\circledR}$ & 18 & 21 & 29 & 28 & 18 \\
\hline Omnitrope ${ }^{\circledR}$ & II & 11 & 14 & 11 & II \\
\hline Nutropin $\mathrm{AQ}^{\circledR}$ & 6 & 11 & 14 & II & 7 \\
\hline Zomacton $^{\circledR}$ & 4 & 9 & 14 & 5 & 8 \\
\hline Saizen $^{\circledR}$ & 8 & 7 & 0 & 7 & 6 \\
\hline Growject $^{\circledR}$ & 2 & 2 & 3 & I & 5 \\
\hline \multicolumn{6}{|c|}{ Therapy duration on previous brand } \\
\hline Mean duration, months & 26.9 & 39.5 & 36.8 & 30.0 & 36.8 \\
\hline
\end{tabular}

Notes: ${ }^{\text {NNorditropin }}{ }^{\circledR}$ devices were available by country as follows: UK and France: FlexPro ${ }^{\circledR}$, SimpleXx ${ }^{\circledR}$ (NordiPen ${ }^{\circledR}$ ), Nordiflex ${ }^{\circledR}$; Italy: Nordiflex ${ }^{\circledR}$ only; Japan: FlexPro ${ }^{\circledR}$ only. For details of other brands/devices in use by country, see Supplementary Figure SI; b Manufacturers of brands are as follows: Genotropin ${ }^{\circledR}-$ Pfizer; Humatrope ${ }^{\circledR}-$ Lilly;

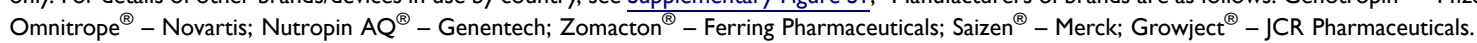

Abbreviation: PRFs, patient report forms. 
clinicians responded that they did not know how adherence compared (Supplementary Figure S4).

Clinicians were also asked to rate their patients' QoL after the switch to Norditropin ${ }^{\circledR}$. They were offered the options of "improved significantly", "improved somewhat", "remained the same", "declined somewhat", "declined significantly", or "unknown" (Supplementary Figure S3). The percentage of respondents who considered that patients' QoL had improved after the switch to Norditropin ${ }^{\circledR}$ (combining the first two categories) was as follows: 63\% (all); 55\% (UK); 63\% (France); 60\% (Italy); and $73 \%$ (Japan). It is important to note that these were the clinicians' own impressions, based on their assessments of the information available to them.

\section{Discussion}

We conducted a market research study among clinicians in four countries who treat pediatric patients with GH-related disorders and who had switched at least one patient to Norditropin ${ }^{\circledR}$ since the start of COVID-19, to establish what factors drove the switches, clinicians' perceptions of the results, and whether useful general lessons could be learned.

The timing of the peaks in switch volume by country (based on the PRFs received) shows that "peak switching" occurred during the first wave of the pandemic in each country, suggesting that clinicians' choices were affected by changed circumstances arising from the pandemic. Virtual consultations accounted for $36 \%$ of visits overall since the start of COVID-19, ranging from $54 \%$ in the UK to $10 \%$ in Japan. Unfortunately, we did not collect data for patient contact format prior to the pandemic. However, it is known that virtual consultations have increasingly replaced in-person healthcare consultations in many countries. ${ }^{8,9}$ The low proportion of virtual consultations in Japan may reflect a lower impact of the pandemic on daily life in that country, or an earlier recovery from the first wave.

We do not have the data to strictly compare numbers of referrals for GH disorders before and after the advent of COVID-19. One of the authors (MC) reports that at his center in Italy, there were $30 \%$ fewer new diagnoses of GHD-related disorders during lockdown compared with the previous year. We speculate that a decrease in referrals has probably occurred in many countries. The reasons may include the fact that, as children are not being seen in the presence of their peers, short stature is less likely to be recognized by carers. It is also very likely that programs of measuring and weighing children as part of routine health surveillance have been negatively impacted by the pandemic.

The survey results may indicate under-treatment of patients, as not all patients with diagnosed or suspected GH-related disorders were actually treated with GH since the start of COVID-19 (Table 2). The survey did not collect data on the proportions of patients with $\mathrm{GH}$ related disorders who were actually treated prior to COVID-19, and we were not able to find any published data on this aspect pre-COVID-19. The proportion of GHrelated disorders actually treated may also vary due to differences in the management and basis for treatment reimbursement of "GH-related disorders" in the different countries (for example, Note 39 of the relevant Italian regulations specifies the inclusion of conditions that are not necessarily included in other countries for hospital admission). ${ }^{10}$

Clinicians' top considerations in deciding on a $\mathrm{GH}$ brand since the start of COVID-19 were patient/carer feedback, the materials provided by companies' patient support programs, and the need for therapies to be easy to use in the context of virtual consultations. Similar themes were rated as most important among key advantages of Norditropin $^{\circledR}$, specifically the ease of use of Norditropin ${ }^{\mathbb{B}}$ devices and their features and benefits, and better patient/ carer feedback. The next most frequently mentioned item, supply issues with the previous therapy, was hopefully a one-off issue that would not usually play a role in prescribing decisions.

Virtual consultations are likely to represent an increasing proportion of all consultations while the pandemic lasts and even afterwards, because perceived cost savings may be attractive to health authorities. However, virtual consultations have limitations, including a potential loss of in-person communication and non-verbal cues, ${ }^{8,9}$ and - in the context of pediatrics - height measurements. If virtual consultations do increasingly become the norm, then ease of use, ease of training users, and support assets will be very important. Norditropin ${ }^{\circledR}$ was the brand cited most often as being suitable for use in all three patient scenarios of virtual consultations, in-person consultations, or a mixture of the two. However, it must also be borne in mind that the respondents had all switched GH therapy to Norditropin ${ }^{\circledR}$ for at least one patient, and are therefore not necessarily representative of all clinicians treating children with GH-related disorders. 
A further challenge with virtual consultations is that of monitoring and maintaining a record of children's height accurately. Companies supplying GH could possibly work with clinicians to find a solution for remote measurement methods that could be included in their patient support programs. Alternatively, local pediatricians could be asked to perform interim face-to-face consultations between delayed endocrinology visits, particularly for patients living in remote areas, or specialists could work with local HCPs to arrange for measurements to be made in local clinics. This possibility further emphasizes the need for easy-to-use and easy-to-train devices that provide accurate dosing. The good experience reported with Norditropin ${ }^{\circledR}$ devices in Japan confirms their acceptability not just to endocrinologists but also to pediatricians.

Among the HCPs surveyed in the current study, $17 \%$ of patients had been switched from one GH brand to another, and approximately two-thirds of switches overall were to Norditropin ${ }^{\circledR}$ from a different GH brand. Extensive longterm efficacy and safety data are available for Norditropin ${ }^{\circledR}, 11,12$ which was first introduced in 1988. The Norditropin ${ }^{\circledR}$ devices used in the countries surveyed here were primarily NordiFlex ${ }^{\circledR}$ and FlexPro ${ }^{\circledR}$, and to a lesser extent SimpleXx ${ }^{\circledR}$ cartridges used with NordiPen ${ }^{\circledR}$ (in the UK and France). All of these devices were designed to be simple and easy to use, and have been highly rated by patients in usability and preference studies. ${ }^{13-18}$ In particular, the size of the FlexPro ${ }^{\circledR}$ pen makes it easy to hold for different sized hands and it has a push dose button requiring less injection force than other devices and an end of dose click to confirm dose delivery. ${ }^{19}$ Other advantages of Norditropin ${ }^{\circledR}$ are the use of a histidine buffer and thin-walled NovoFine ${ }^{\circledR}$ needles to minimize pain, ${ }^{20,21}$ and the availability for most Norditropin ${ }^{\circledR}$ devices of PenMate ${ }^{\circledR}$, an optional accessory that hides the needle and automates needle insertion. ${ }^{22}$

For the patients who had switched to Norditropin ${ }^{\circledR}$, the majority of clinicians overall rated Norditropin ${ }^{\circledR}$ favorably in terms of the level of training and/or support required from HCPs. Based on patient/carer feedback, clinicians were of the opinion that most patients/carers considered Norditropin ${ }^{\circledR}$ superior to or no different than the previous therapy. Regarding adherence, $42 \%$ of clinicians considered adherence to treatment to be better with Norditropin ${ }^{\circledR}$ versus previous therapy, with $50 \%$ assessing that there was no difference and $6 \%$ saying they did not know. Clinicians also estimated that patients' QoL had improved after the switch to Norditropin ${ }^{\circledR}$. The survey did not question respondents on the reasons for their assessments of improved QoL, and relied on respondents' memory, which may have resulted in a recall bias. Direct patient feedback on adherence and QoL would clearly have been preferable, but preliminary investigation showed that it was not feasible to obtain a sufficient sample size within the required timeframe.

The data provide some interesting comparisons between different countries and age groups for this group of patients, bearing in mind that they are based on a selfselected sample of clinicians, and only on the submitted PRFs for patients switched to Norditropin ${ }^{\circledR}$. Patients' mean age was 9.2 years overall, ranging from 8.6 in Japan to 10.1 years in the UK. The lower mean age in Japan may reflect the fact that many patients are seen and managed by pediatricians rather than endocrinologists, possibly reducing the time from presentation to diagnosis and treatment. The majority (57\%) of the PRFs for switched patients overall were for the youngest age group, possibly because patients new to therapy may need to try more than one device before the patient/carer feels at ease administering injections. Conversely, the older age group accounted for the lowest proportion of switches to Norditropin ${ }^{\circledR}$ in all countries. Older children may be more established on their GH device and therefore less likely to consider a switch.

Among the submitted PRFs, the percentage of male patients was $62 \%$ overall, ranging from $57 \%$ in Italy to $71 \%$ in Japan. This preponderance of male patients does not suggest any bias in treatment switches but is in line with the gender distribution of GH-treated patients reported in earlier studies on GH disorders. For example, NordiNet International Outcome Study (NordiNet IOS) and the American Norditropin Studies: Web-Enabled Research Program (ANSWER) were long-term observational studies that assessed the effectiveness and safety of real-world treatment with Norditropin ${ }^{\circledR}$ for up to 10 years in 22 European countries and up to 14 years in the USA. In these studies, boys accounted for $57 \%$ and $69 \%$ of patients, respectively. ${ }^{11} \mathrm{~A}$ similar finding was reported from a long-term observational study of Genotropin ${ }^{\circledR}$ in Europe, the USA, and Japan. ${ }^{23}$

In Italy, differences in local treatment rules, the availability of devices, and regulatory system changes and regional tenders may have contributed to a large proportion of patients initiating new GH therapy or switching to a different therapy. 
A limitation of this study, already mentioned above, is that respondents were, by definition, clinicians who had switched at least one patient to Norditropin ${ }^{\circledR}$ during the survey period. Furthermore, the patient data presented is only a "snapshot" of patients who had switched to Norditropin $^{\circledR}$, as clinicians were asked to submit no more than three PRFs (so that the survey would not be too burdensome for respondents). In the light of this limited number of clinicians and PRFs, we considered that statistical analyses of differences between groups would not be meaningful.

Further limitations are that respondents may have been restricted in their choice of therapy by local guidelines or formularies, and that patients' QoL post-switch was reported by the treating clinicians and not by the patients themselves. Despite these limitations, the survey provides an interesting indication of factors affecting treatment decisions during the COVID-19 pandemic in 2020, and how these decisions compared between the four countries.

\section{Conclusion}

Clinicians in four countries who had switched at least one pediatric patient to Norditropin ${ }^{\circledR}$ since the start of COVID19 were surveyed. Respondents rated ease of use and acceptability to patients and carers as key considerations in prescribing GH therapy. Ease in training patients/carers in the use of therapy is particularly important in a setting of virtual consultations, which may increasingly be the "new normal" as a result of the COVID-19 pandemic. Norditropin ${ }^{\circledR}$ was the therapy most frequently identified by respondents as their preferred choice for virtual or inperson consultations or a mixture of both.

\section{Data Sharing Statement}

The relevant data from this survey are contained in the article and supplementary materials.

\section{Acknowledgments}

The authors thank all the respondents to the survey. They also thank Anna Nicholls, Research Director, Instar, for data analytics support. Medical writing and submission support for this manuscript was provided by Grace Townshend and Liz Beatty of Bioscript Medical, UK, and funded by Novo Nordisk Health Care AG, Switzerland.

\section{Author Contributions}

All authors made a significant contribution to the work reported, whether that is in the conception, study design, execution, acquisition of data, analysis and interpretation, or in all these areas; took part in drafting, revising or critically reviewing the article; gave final approval of the version to be published; have agreed on the journal to which the article has been submitted; and agree to be accountable for all aspects of the work in ensuring that questions related to the accuracy or integrity of any part of the work are appropriately investigated and resolved.

\section{Funding}

This study was commissioned by Novo Nordisk Health Care AG, Switzerland, and designed by the sponsor in collaboration with Instar (a market research company).

\section{Disclosure}

J Blair has received payment for membership of the Publication Steering Committee of the NordiNet $^{\mathbb{R}}$ International Outcome Study, sponsored by Novo Nordisk. She has received honoraria for presentations given at scientific meetings sponsored by Novo Nordisk and sponsorship for attending a scientific meeting. $\mathrm{K}$ Warth is an employee of Instar, a preferred market research supplier for Novo Nordisk, which was commissioned by Novo Nordisk to carry out the survey and analyze the results. Y Suvarna is an employee of Novo Nordisk. M Cappa has received honoraria from Novo Nordisk for presentations given at scientific meetings and membership of a Scientific Board, and sponsorship to attend a scientific meeting. The authors report no other conflicts of interest in this work.

\section{References}

1. Kremidas D, Wisniewski T, Divino VM, et al. Administration burden associated with recombinant human growth hormone treatment: perspectives of patients and caregivers. J Pediatr Nurs. 2013;28 (1):55-63. doi:10.1016/j.pedn.2011.12.006

2. Meinhardt U, Eiholzer U, Seitz L, Bøgelund M, Kappelgaard AM. Parent preference in Switzerland for easy-to-use attributes of growth hormone injection devices quantified by willingness to pay. Expert Rev Med Devices. 2014;11(1):31-38. doi:10.1586/17434440.2014.856754

3. Fisher BG, Acerini CL. Understanding the growth hormone therapy adherence paradigm: a systematic review. Horm Res Paediatr. 2013;79 (4):189-196. doi:10.1159/000350251

4. Collett-Solberg PF, Ambler G, Backeljauw PF, et al. Diagnosis, genetics, and therapy of short stature in children: a growth hormone research society international perspective. Horm Res Paediatr. 2019;92(1):1-14. doi:10.1159/000502231

5. Wilson TA, Rose SR, Cohen P, et al. Update of guidelines for the use of growth hormone in children: the Lawson Wilkins pediatric endocrinology society drug and therapeutics committee. $J$ Pediatr. 2003;143(4):415-421. doi:10.1067/S0022-3476(03)00246-4 
6. Rohrer TR, Horikawa R, Kappelgaard AM. Growth hormone delivery devices: current features and potential for enhanced treatment adherence. Expert Opin Drug Deliv. 2017;14(11):1253-1264. doi:10.1080/17425247.2017.1243526

7. Prader-Willi Syndrome Association. Latest update on the genotropin mini quick shortage from Pfizer Pharmaceuticals; 2020. Available from: https:/www.pwsausa.org/latest-update-on-the-genotropin-mini -quick-shortage-from-pfizer-pharmaceuticals/. Accessed May, 2021.

8. Webster P. Virtual health care in the era of COVID-19. Lancet. 2020;395(10231):1180-1181. doi:10.1016/S0140-6736(20)30818-7

9. Glazier RH, Green ME, Wu FC, Frymire E, Kopp A, Kiran T. Shifts in office and virtual primary care during the early COVID-19 pandemic in Ontario, Canada. CMAJ. 2021;193(6):E200-e210. doi:10.1503/cmaj.202303

10. AIFA Italian Medicines Agency. Note 39. Drug note: somatropin; 2021. Available from: https://www.aifa.gov.it/en/nota-39. Accessed May, 2021.

11. Sävendahl L, Polak M, Backeljauw P, et al. Treatment of children with $\mathrm{GH}$ in the United States and Europe: long-term follow-up from NordiNet ${ }^{\circledR}$ IOS and ANSWER program. J Clin Endocrinol Metab. 2019;104(10):4730-4742. doi:10.1210/jc.2019-00775

12. Sävendahl L, Polak M, Backeljauw P, et al. Long-term safety of growth hormone treatment in childhood: two large observational studies NordiNet ${ }^{\circledR}$ IOS and ANSWER. J Clin Endocrinol Metab. 2021;106(6):1728-1741. doi:10.1210/clinem/dgab080

13. Tauber M, Jaquet D, Jesuran-Perelroizen M, Petrus M, Bertrand AM, Coutant R. User assessment of Norditropin NordiFlex $\left({ }^{\circledR}\right)$, a new prefilled growth hormone pen: a Phase IV multicenter prospective study. Patient Prefer Adherence. 2013;7:455-462. doi:10.2147/PPA. S43460

14. Stanhope R, Buchanan C, Butler G, et al. An open-label acceptability study of Norditropin SimpleXx-a new liquid growth hormone formulation. $J$ Pediatr Endocrinol Metab. 2001;14(6):735-740. doi:10.1515/JPEM.2001.14.6.735

15. Rohrer TR, Winter F, Qvist M, Kappelgaard AM. Comparison of intuitiveness, ease of use and preference among three prefilled, disposable growth hormone injection pens. Expert Opin Drug Deliv. 2013;10(12):1603-1612. doi:10.1517/17425247.2013.829451
16. Pfützner A, Hartmann K, Winter F, Fuchs GS, Kappelgaard AM, Rohrer TR. Intuitiveness, ease of use, and preference of a prefilled growth hormone injection pen: a noninterventional, randomized, open-label, crossover, comparative usability study of three delivery devices in growth hormone-treated pediatric patients. Clin Ther. 2010;32(11):1918-1934. doi:10.1016/j.clinthera.2010.10.010

17. Drent ML, Jakobsdottir S, van Wijk JAE, Oostdijk W, Wit JM. Acceptability of liquid human growth hormone (hGH) [Norditropin Simple $\left.\mathrm{Xx}^{\circledR}\right]$ in adults and children with GH deficiency and children with chronic renal disease. Clin Drug Investig. 2002;22(9):633-638. doi:10.2165/00044011-200222090-00008

18. Kappelgaard AM, Mikkelsen S, Bagger C, Fuchs GS. Children and adolescent acceptability of a new device system to administer human growth hormone-a pilot study. J Pediatr Endocrinol Metab. 2012;25 (3-4):285-294. doi:10.1515/jpem-2011-0395

19. Fuchs GS, Mikkelsen S, Knudsen TK, Kappelgaard AM. Ease of use and acceptability of a new pen device for the administration of growth hormone therapy in pediatric patients: an open-label, uncontrolled usability test. Clin Ther. 2009;31(12):2906-2914. doi:10.1016/j.clinthera.2009.12.014

20. Laursen T, Hansen B, Fisker S. Pain perception after subcutaneous injections of media containing different buffers. Basic Clin Pharmacol Toxicol. 2006;98(2):218-221. doi:10.1111/j.17427843.2006.pto_271.x

21. Iwanaga M, Kamoi K. Patient perceptions of injection pain and anxiety: a comparison of NovoFine 32-gauge tip $6 \mathrm{~mm}$ and Micro Fine Plus 31-gauge 5mm needles. Diabetes Technol Ther. 2009;11 (2):81-86. doi:10.1089/dia.2008.0027

22. Hokken-Koelega A, Keller A, Rakov V, Kipper S, Dahlgren J. Patient acceptance, ease of use, and preference for Norditropin NordiFlex with NordiFlex PenMate: results from an open-label, user survey of everyday use. ISRN Endocrinol. 2011;2011:803948. doi:10.5402/ 2011/803948

23. Ranke MB, Lindberg A, Tanaka T, Camacho-Hübner C, Dunger DB, Geffner ME. Baseline characteristics and gender differences in prepubertal children treated with growth hormone in Europe, USA, and Japan: 25 years' KIGS ${ }^{\circledR}$ experience (1987-2012) and review. Horm Res Paediatr. 2017;87(1):30-41. doi:10.1159/000452887
Patient Preference and Adherence

\section{Publish your work in this journal}

Patient Preference and Adherence is an international, peer-reviewed, open access journal that focusing on the growing importance of patient preference and adherence throughout the therapeutic continuum. Patient satisfaction, acceptability, quality of life, compliance, persistence and their role in developing new therapeutic modalities and compounds to optimize clinical outcomes for existing disease states are major areas of interest for the journal. This journal has been accepted for indexing on PubMed Central. The manuscript management system is completely online and includes a very quick and fair peer-review system, which is all easy to use. Visit http:// www.dovepress.com/testimonials.php to read real quotes from published authors. 